scription. This category of membership is confined to those practitioners who do not engage in any form of clinical work and whose duties are in no way related to the diagnosis and treatment of patients or groups of patients. Full details of this form of membership are available to any interested practitioner.

The examination of an applicant for insurance or disablement benefit does constitute clinical work, as the practitioner is required to exercise his clinical judgement. Similarly a practitioner who is a member of a medical board is not eligible for this form of membership, as he also has to exercise his clinical judgement. One would have thought that the dermatologist would be among the least vulnerable to litigation, but even so the Union has just settled for $£ 27,000$ a claim that arose out of the treatment prescribed by a dermatologist.

To introduce a scale of subscriptions based on the nature of practitioners' professional work would create endless problems. The President of Le Sou Medical, which is the French counterpart of the M.D.U. and whose objects are identical with those of the M.D.U., has often said that he regrets that his organization has differential rates of subscription of this kind, as the system is fraught with many difficulties. The M.D.U. does not now charge an entrance fee-this was abolished many years ago.

There is no need for a practitioner to continue to pay his subscriptions for several years after retirement, as Dr. Turner has alleged. The only criterion to be satisfied when a member applies for assistance is that he must have been a fully paid-up member when the incident took place out of which the threatened claim or litigation has arisen. When a practitioner informs the office that he has retired from practice he is advised to apply for retired life membership and he is not required to make any further payment. There is no question of the M.D.U. refusing to defend a retired life member who is faced with a claim relating to the time when he was a fully paid-up member.

Dr. Turner refers to married women doctors who do only a small amount of work -for example, family planning clinics. The suggestion that doctors who are engaged in F.P.A. work or undertake school clinics are unlikely to become involved in litigation cannot be supported, as our experience shows. One of the objects of the grant that is made to women practitioners under the women doctors' retainer scheme $e^{1}$ is to enable them to keep up their registration and their membership of a medical defence organization.

The Union has a membership of 72,000 , and since the notification in June of the increased subscription only 23 members have written to complain about the increase. It is significant that for the sort of cover which the M.D.U. provides an insurance company would charge a premium very much greater than the Union's subscription. Furthermore, it is doubtful whether any insurance company would reduce its premium for nonclinical doctors.-I am, etc.,

Philip H. Addison Medical Defence Union

London W.C.1 Memorandum H.M.

Department
$(72142,1972$.

\section{Immunodiagnosis of Cancer}

SIR,-The letter from Dr. E. J. Field and colleagues (9 September, p. 641) describes how the macrophage electrophoretic migration method of measuring cellular sensitization to a cancer basic protein and to encephalitogenic factor might be used in early diagnosis of malignancy. The authors have demonstrated that mothers who have cancer at the time of pregnancy transmit lymphocytes sensitized against the cancer basic protein during gestation and that such lymphocytes are still present 12 years and longer after birth. In our laboratory lymphocytes sensitive to autologous tumour cell antigens have been demonstrated by the leucocyte migration test with quite different results.

The antigens used in our tests are prepared from operation specimens (five carcinomas of the bronchus and one carcinoma of the colon to date) by first trypsinizing the solid tumour and then gently homogenizing the tumour cells. Gradient centrifugation is employed to obtain a fraction of tumour cell membranes, and normal lung or colon is treated in the same way to obtain normal cell membranes for control studies. Leucocyte migration tests ${ }^{1}$ are performed on blood samples obtained at weekly intervals after operation.

Of the six tumours studied so far five have shown significant inhibition of migration seven days after operation, but by day 21 a depletion of the tumour-sensitive lymphocyte population appears to have occurred, since inhibition of migration by tumour antigens is no longer observed. These five patients were considered to have local tumour at least completely resected, are all recovering normally from operation, and appear to have no residual tumour to maintain lymphocyte sensitivity. Inhibition of migration of leucocytes from the sixth patient was observed on days $7,14,21$, and 28 , with apparently no depletion of tumour-sensitive lymphocytes. This patient still runs a "stormy" postoperative course and may have residual tumour, since an antigenic stimulus appears to be still present.

These preliminary studies have indicated, then, that tumour-sensitive lymphocytes capable of producing leucocyte migration inhibition factor on incubation with specific antigen are very short-lived and are quite different from those responsible for producing macrophage electrophoretic migration inhibition factor.-I am, etc.,

\section{Tenovus Research Laboratories,}

Welindre Hospital,

B. M. JoNES 1 Federlin, K., Maini, R. N., Russell, A. S., and
Dumnode, D. C., Fournal of Clinical Pathology,
1971, 24, 533.

SIR,-Lymphocytes from individuals with malignant disease show special sensitization to encephalitogenic factor (E.F.)-a basic protein extractable from human brain ${ }^{2}-$ and to an even greater extent to a similar basic protein which can be prepared similarly from a variety of malignant (but not benign) human neoplasms. ${ }^{2} 3$ Attempts have been made to isolate the antigenic protein and its active peptide 4 both from naturally occurring human tumours (for example, stomach, breast, lung) and from HeLa cells in culture, the latter being derived, of course, from a human cancer of the cervix uteri.

While HeLa cells were found to be a good source of tumour basic protein (Ca.B.P.) from which active peptide could then be prepared, it was found that WI 38 cells in culture (Biocult: human embryonic lung) likewise behaved as if they were endowed with Ca.B.P. even though they are generally regarded as a non-malignant line of cells. The method of determining lymphocyte sensitization was the macrophage electrophoretic migration (M.E.M.) test described by Caspary and Field ${ }^{3}$ in detail with an original protocol in extenso. In principle the method depends on the observation that lymphocytes brought into contact with antigen to which they are sensitized produce a macrophage slowing faotor (M.S.F.-perhaps identical with M.I.F.) with the property of causing normal guinea-pig macrophages to travel more slowly in an electric field. These cells may thus be used as an indicator system for antigenlymphocyte interaction. If $t_{c}=$ migration time of the normal guinea-pig macrophages when mixed with cancer lymphocytes alone, $t_{e}=$ migration time when antigen (Ca.B.P.) is also present, then $t_{e}>t_{c}$ and $t^{e}-t_{c} / t_{c} \times 100$ is a measure of the slowing and so of the lymphocyte-antigen interaction-that is, of lymphocyte sensitization to Ca.B.P.

As opposed to extracts of cancerous tissue preparations made similarly from normal tissue (for example, that adjacent to a tumour) gave a clear but lesser reaction with cancer lymphocytes. In general Ca.B.P. gave about $15 \%$ macrophage slowing with cancer lymphocytes $^{3}$ while a similar basic protein prepared from normal tissues gave about $9-10 \%$. The question arose whether normal cells in tissue culture (such as WI 38 were presumed to be) might give a different reaction with cancer lymphocytes from that given by the same cells immediately after removal from the body. In other words, did removal from the constraints of "tissue context" lead to the appearance of new antigenic determinant(s) either similar to or identical with those found on cancer cells? This was tested with human fetal lung tissue.

Fragments of fetal lung were dissociated mechanically by cutting up finely and straining through a stainless-steel filter. Aliquots of the cell suspension were put in culture in $10 \%$ fetal calf serum in TC 199 , including penicillin 100 units $/ \mathrm{ml}$, streptomycin $100 \mu \mathrm{g} / \mathrm{ml}$, fungizone $1 \mu \mathrm{g} / \mathrm{ml}$, and fresh L-glutamine at $0.03 \%$ medium, at $37^{\circ}$ for varying periods. Cultures were killed by sudden chilling to $-70^{\circ} \mathrm{C}$ and equal numbers of the killed original lung cells and those which had been in culture were used as antigen for stimulation of lymphocytes from a given cancer patient. As control the cancer lymphocytes were tested with a known active basic protein extract of a carcinoma of the cervix. Experiment has repeatedly shown that while lung tissue removed from the fetus and frozen at once always gave a "normal tissue response" with cancer lymphocytes (that is, 9-10\% macrophage slowing) once the lung cells had been maintained in culture for 24 hours they gave a "cancer type reaction"-that is, about $15 \%$ slowing, equal to that produced by Ca.B.P. itself.

Further experiments showed that maintenance of the lung cells in vitro at $37^{\circ} \mathrm{C}$ for so short a period as 5.5 hours resulted in raising the stimulation they provided to cancer patient lymphocytes. By 11 hours the full cancer response was evoked and thereafter maintained (see Table). Nor was the change in antigenic 